\title{
IMPLEMENTASI LOGIKA FUZZY PADA ENEMY BEHAVIOUR GAME PETUALANGAN SIDE SCROLLER 2D (SAVE FOREST INDONESIA)
}

\author{
Ba'ar Wasil Razzaq ${ }^{1}$, Hendra Pradibta ${ }^{2}$, CahyaRahmad $^{3}$ \\ Jurusan Teknologi Informasi, Program Studi Teknik Informatika,Politeknik Negeri Malang \\ 1․ baarwasilrazzaq888@gmail.com, ${ }^{2}$ ndropradibta@gmail.com, ${ }^{3}$ cahya_rahmad@yahoo.com
}

\begin{abstract}
Abstrak
Game selain hanya digunakan untuk bermain, game juga memiliki sisi edukasi dan pembelajaran, karena game tidak hanya menyenangkan di mainkan tetapi ada ilmu yang juga didapat oleh masyarakat. Peneliti membuat sebuah game berdasarkan keadaan hutan yang saat ini terjadi di Indonesia. Dengan menggunakan media pembelajaran edukasi digunakan untuk memberi pengetahuan tentang jenis hutan dan manfaatnya agar game menjadi lebih menarik. Maka dari itu dilakukan pemberian pop-up tentanginformasihutan yang ada di Indonesia dancaramenjaganya agar tetaplestari.

Dalam penelitian ini, dirancang penerapan logika Fuzzy Sugeno untuk mengatur perilaku musuh, pada game bertipe Adventure yang berjudul "Save Forest Indonesia". Terdapat 2 jenis musuh, yaitu tipe jarak dekat, dan jarak jauh. Musuh ini memiliki parameterinput fuzzy yaitu jarak, dia akan mendekat jika player dekat dengan jarak musuh.

Penerapan fuzzy dalam permainan ini telah berjalan dengan baik, dimana musuh tipe jarak dekat menjadi cukup agresif (90\% perilaku menyerang), dan tipe jarak jauh agresif menembak jika player mendekat $(90 \%$ perilaku menyerang).
\end{abstract}

Kata Kunci: Game, Edukasi, Adventure, Logika Fuzzy Sugeno.

\section{Pendahuluan}

Hutan merupakan sumber daya alam yang tidak ternilai karena didalamnya terkandung keanekaragaman hayati sebagai sumber sumber oksigen terbesar, sumber hasil hutan kayu dan nonkayu, pengatur tata air, pencegah banjir, dan erosi serta kesuburan tanah, perlindungan alam hayati untuk kepentingan ilmu pengetahuan, kebudayaan, rekreasi, pariwisata dan sebagainya. Karena itu pemanfaatan hutan dan perlindungannya telah diatur dalam UUD 45, UU No. 5 tahun 1990, UU No 23 tahun 1997, UU No. 41 tahun 1999, PP No 28 tahun 1985 dan beberapa keputusan Menteri Kehutanan serta beberapa keputusan Dirjen PHPA dan Dirjen Pengusahaan Hutan. Namun gangguan terhadap sumber daya hutan terus berlangsung bahkan intensitasnya makin meningkat.

Kerusakan hutan yang meliputi kebakaran hutan, penebangan liar dan lainnya merupakan salah satu bentuk gangguan yang makin sering terjadi. Dampak negatif yang ditimbulkan oleh kerusakan hutan cukup besar mencakup kerusakan ekologis, menurunnya keanekaragaman hayati, merosotnya nilai ekonomi hutan dan produktivitas tanah, perubahan iklim mikro maupun global, dan asap dari kebakaran hutan mengganggu kesehatan masyarakat serta mengganggu transportasi baik darat, sungai, danau, laut dan udara. Dan juga gangguan asap karena kebakaran hutan Indonesia akhir-akhir ini telah melintasi batas negara.
Dari permasalahan tersebut, solusi yang tepat untuk itu adalah penulis membuat game yang dibuat sebagai pembelajaran edukatif dan sebagai media informasi, untuk menunjukkan ke masyarakat agar menjaga kelestarian hutan di Indonesia. Game yang dibuat oleh sebagian industry kurang adanya efek positif bagi para pemain, seperti terlalu focus pada efek pertempuran yang begitu apik, serta service-service yang disediakan, sehingga pemain kurang mengetahui adanya pembelajaran edukatif serta nilai-nilai positif yang terkandung pada game itu sendiri. Penulis akan merancang sebuah game yang bergenre adventure dengan judul "Implementasi Logika Fuzzy Pada Enemy Behavior Game Petualangan Side Scroller 2d (Save Forest Indonesia)". Pada permainan yang dirancang pada penelitian ini diimplementasikan logika fuzzy untuk mengatur perilaku musuh. Logika fuzzy adalah cabang dari sistem kecerdasan buatan (Artificial Intelligence) yang mengemulasi kemampuan manusia dalam berfikir ke dalam bentuk algoritma yang kemudian dijalankan oleh mesin.

namun masih minimnya game aplikatif yang mampu mengedukasi sekaligus mensosialisasikan pentingnya peduli terhadap lingkungan.

\subsection{Rumusan Masalah}

Bagaimana membuat game petualangan Side Scroller $2 d$ menjadi media informasi dan sebagai 
pembelajaran edukatif yang menarik bagi masyarakat?

Tujuan yang dicapai dalam penelitian ini adalah membuat game yang dapat menjadi media informasi dan pembelajaran edukatif dalam menjaga kelestarian hutan dengan menggunakan metode logika fuzzy untuk merubah perilaku musuh sesuai tindakan manusia dalam berfikir pada bentuk algoritma.

Agar pembahasan lebih terarah, maka penulis memberikan batasan-batasan pembahasan masalah, yaitu :

a. Game berbasis Android

b. PermaiananSingle Player

c. Merupakan game 2 dimensidengan genre Adventure

d. Game ditujukan kepada semua kalangan masyarakat di atas umur 6 tahun

\section{Metodologi Penelitian}

Dalam merancang game Save Forest Indonesiadigunakan metodologi pengembangan Multimedia Life Cycle. Menurut Sutopo (2003) metodologi ini terdiri dari 6 tahap yaitu konsep, desain, sebagai berikut.

\subsection{Konsep (Concept)}

Tahapan pada proses ini meliputi pembuatan konsep mengenai game yang akan dibuat seperti menentukan target pengguna, menentukan jenis game (2 dimensi atau 3 dimensi) menentukan tema dari game yang akan dibuat seperti pada penelitian ini dimana tema atau konsep dari game adalah mengenai peduli lingkungan terhadap pencemaran lingkungan yang disebabkan oleh sampah organik maupun anorganik, serta merancang gameplay yang akan dimasukkan kedalam game.

\subsection{Perancangan (Design)}

Setelah konsep terbentuk langkah selanjutnya adalah prose perancangan. Berdasarkan topik yang diambil yaitu mengenai kebersihan lingkungan maka diangkatlah judul rancang bangun game Save Forest IndonesiaSetelah penentuan topik, pembuatan alur dari game, dan perancangan game melalui storyboard dan flowchart. Proses yang dilakukan pada tahap ini adalah juga menentukan karakter dan objek yang akan dibuat pada game Save Forest Indonesia, karakter dan objek yang akan dibuat adalah:
- 1 player
- 3macammusuhdarat
- 1 macammusuhterbang

Sedangkan objek atau lingkungan yang akan dibuat adalah :

- Pepohonan

- Spike

- Flyng ground
Tabel 1. StoryBoard

\begin{tabular}{|c|c|}
\hline Storyboard & Keterangan \\
\hline $\begin{array}{l}\text { HalamanAwal } \\
\text { SAFE FOREST } \\
\text { IIDOMESIA } \\
\text { (8) } x\end{array}$ & $\begin{array}{l}\text { Pada halaman awal } \\
\text { game player akan } \\
\text { disuguhkan dengan } \\
\text { menu-menu seperti : } \\
\text { - Start } \\
\text { - Select Level } \\
\text { - PetunjukPermainan } \\
\text { - Exit,digunakan } \\
\text { untuk keluar dari } \\
\text { game }\end{array}$ \\
\hline PetunjukPermainan & \begin{tabular}{lrr} 
Petunjuk & ini & akan \\
memberi & \multicolumn{1}{r}{ informasi } \\
kepada user & tentang \\
petunjuk cara & bermain \\
dan petunjuk & cara \\
mendapatkan & sebuah \\
informasi & & yang \\
tersimpan di & setiap \\
papan & &
\end{tabular} \\
\hline $\begin{array}{l}\text { Pop Up Information } \\
\text { a }\end{array}$ & $\begin{array}{l}\text { Halaman ini berisi } \\
\text { informasi jenis hutan } \\
\text { yang akan dimainkan, di } \\
\text { setiap pop up akan } \\
\text { terdapat informasi } \\
\text { tentang hutan tersebut. }\end{array}$ \\
\hline - & 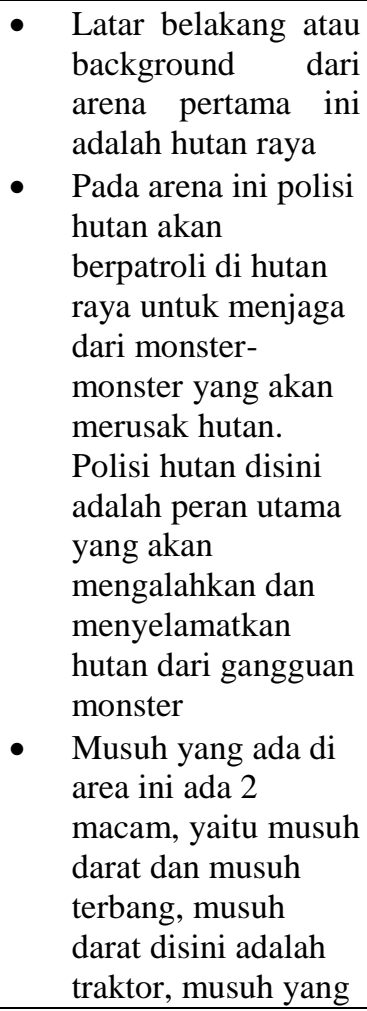 \\
\hline
\end{tabular}




\begin{tabular}{|c|c|}
\hline & $\begin{array}{l}\text { akan menebang } \\
\text { pepohonan, musuh } \\
\text { kedua adalah } \\
\text { kelelawar, yang } \\
\text { akan merusak } \\
\text { pepohonan dengan } \\
\text { cara melubanginya. } \\
\text { Untuk menentukan } \\
\text { tingkah laku } \\
\text { serangan digunakan } \\
\text { implemantasi logika } \\
\text { fuzzy pada setiap } \\
\text { musuh sebagai } \\
\text { kecerdasan buatan }\end{array}$ \\
\hline $\begin{array}{c}\text { Level } 2 \\
1 \times 1 y \\
\end{array}$ & $\begin{array}{l}\text { Latarbelakang atau } \\
\text { background dari } \\
\text { arena pertama ini } \\
\text { adalah hutan hujan } \\
\text { Musuh yang ada di } \\
\text { area ini ada } 2 \\
\text { macam, yaitu musuh } \\
\text { darat dan musuh } \\
\text { terbang, musuh } \\
\text { darat disini adalah } \\
\text { oil industry yang } \\
\text { akan membuat } \\
\text { hutan menjadi } \\
\text { tempat pembuangan } \\
\text { limbah, musuh yang } \\
\text { akan menebang } \\
\text { pepohonan, musuh } \\
\text { kedua adalah } \\
\text { kelelawar, yang } \\
\text { akan merusak } \\
\text { pepohonan dengan } \\
\text { cara melubanginya. } \\
\text { Untuk menentukan } \\
\text { tingkah laku } \\
\text { serangan digunakan } \\
\text { implemantasi logika } \\
\text { fuzzy pada setiap } \\
\text { musuh sebagai } \\
\text { kecerdasan buatan. }\end{array}$ \\
\hline 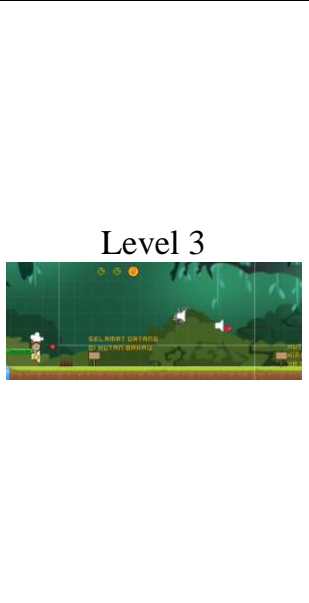 & 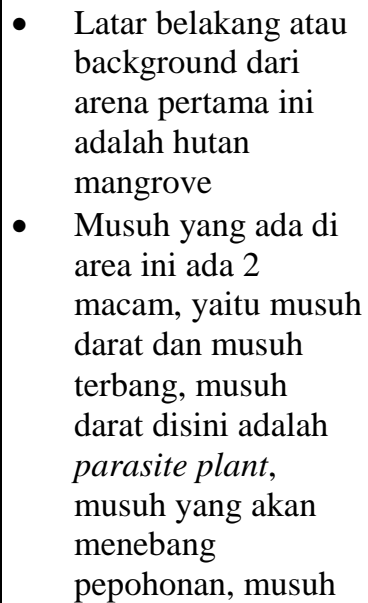 \\
\hline
\end{tabular}

\begin{tabular}{|l|l|}
\hline & kedua adalah \\
kelelawar, yang \\
akan merusak \\
pepohonan dengan \\
cara melubanginya. \\
• Untuk menentukan \\
tingkah laku \\
serangan digunakan \\
implemantasi logika \\
fuzzy pada setiap \\
musuh sebagai \\
kecerdasanbuatan. \\
\hline
\end{tabular}

Setelah proses-proses diatas selesai, maka proses yang akan dilakukan selanjutnya adalah pemodelan karakter 2D, pembuatan animasi karakter, pemodelan lingkungan game 2D, penulisan source code game, serta implementasi kecerdasan buatan kedalam game.

\subsection{Perhitungan Perancangan Metode Fuzzy}

MetodeFuzzy yang digunakan untuk menghasilkan keluaran yang berupa hasil sebagai berikut :

- Buat Membership Function berdasarkan keanggotaan yang dibutuhkan sesuai dengan permasalahan yang ada.

- Input nilai sesuai dengan Membership Function yang sudah tersedia.

- Lalu hitung menggunakan rumus fungsi keanggotaan yang sesuai dengan Membership Function yang ada.

$$
\begin{gathered}
(\mu-a) /(b-a) ; a<\mu \leq b \\
(\mu-c) /(c-b) ; b<\mu \leq c
\end{gathered}
$$

- Setelah itu akan mendapatkan Fuzzy Input dari masing - masing Membership Function.

- Lalu aplikasikan Fuzzy Input yang dihasilkan dari masing - masing Membership Function kesemua Inference / Rule yang sesuai dengan Inference / Rule yang tersedia.

- Hasil dari rule yang terpilihakan di implikasika menggunakan fungsi minimum atau AND.

- Lalu dicari hasil dari implikasi tersebut yang akan digunakan dalam proses Defuzzifikasi. 


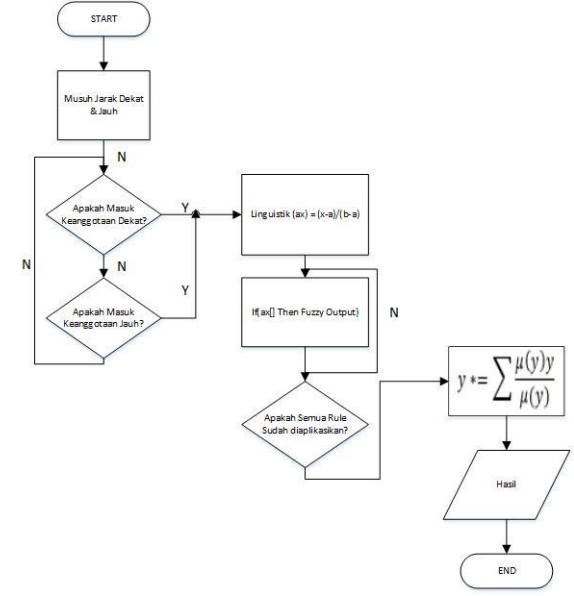

Gambar 2 Flowchart Perhitungan Fuzzy

\subsection{Perancangan Perhitungan}

Pada pembuatan system ini digunakan metode Fuzzy untuk implementasi perilaku musuh terhadap player, berikut ini perhitungan dan perancangan dari system pada enemy di dalam game ini :

1. Enemy Darat dan Terbang berpengaruh mulai menyerang jika player mendekat dengan jarak 5 pixel.

2. Enemy jarak dekat dan jauh akan menjauh jika player melewatinya dari jarak 5 pixel.

3. Input nilai jarak tersebut pada fungsi keanggotaan yang ada.

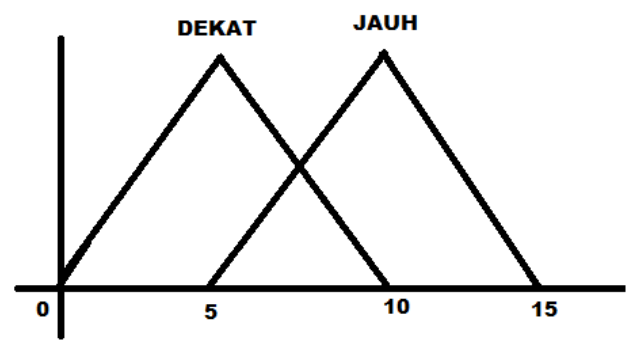

Gambar 2 Fungsi Keanggotaan Jarak

4. Lalu hitung input jarak tersebut dengan mengguakan rumus fungsi keanggotaan agar mendapatkan fuzzy input.

$$
\begin{gathered}
(\mu-a) /(b-a) ; a<\mu \leq b \\
(\mu-c) /(c-b) ; b<\mu \leq c
\end{gathered}
$$

5. Aplikasikan hasil fuzzy input kedalam semua rule yang ada, lalu cocokan dengan rule yang sesuadengan hasil.

- If enemy Terbang = "Dekat" dengan player Then = "Menembak"

- If enemy Terbang = "Jauh" dengan player Then = "Stay"

- If enemy Darat = "Dekat" dengan player Then = "Menyerang"

- $\quad$ If enemy Darat = "Jauh" dengan player Then = "Stay"
6. Hasil dari implikasi rule tersebut digunakan sebagai untuk proses Defuzifikasi dengan menggunakan HeightMethod atau mencari nilai maksimum dari implikasi tersebut, dengan output variabel linguistik. Atau menggunakan WeightOfAverage dengan rumus sebagai berikut :

$$
y *=\sum \frac{\mu(y) y}{\mu(y)}
$$

\subsection{Pengujian}

Uji coba (Testing) pada aplikasi game dilakukan dengan melakukan pengujian alfa dan betha. Pengujian alfa adalah pengujian yang dilakukan untuk memeriksa fungsionalitas dari sebuah aplikasi.

Pengujian betha dilakukan dengan melibatkan pihak lain yaitu dengan melakukan demo game kepada calon user dan melakukan pengisian kuesioner kepada 20 orang user.

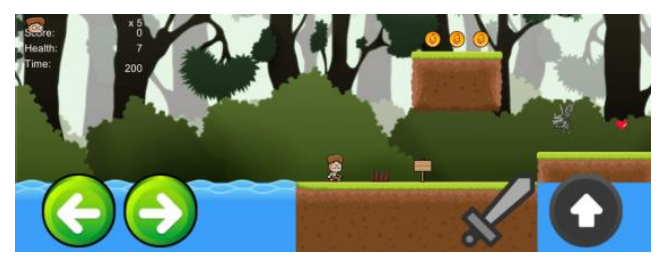

Gambar 3. Level 1

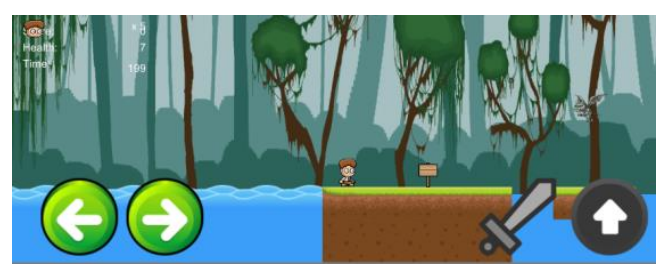

Gambar4. Level 2

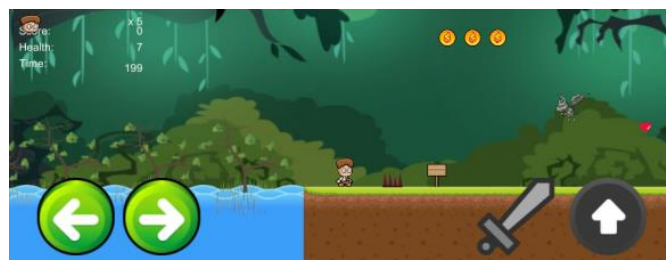

Gambar 5. Level 3

\subsection{Distribusi (Distribution)}

Pada tahap ini proyek yang sudah selesai kemudian dilakukan pemaketan aplikasi. Game dikemas kedalam android package (.apk)sehingga ukuran file menjadi lebih kecil dari yang sebenarnya, setelah itu game yang telah dipaketkan ini dapat di upload kedalam Google Play Store. 


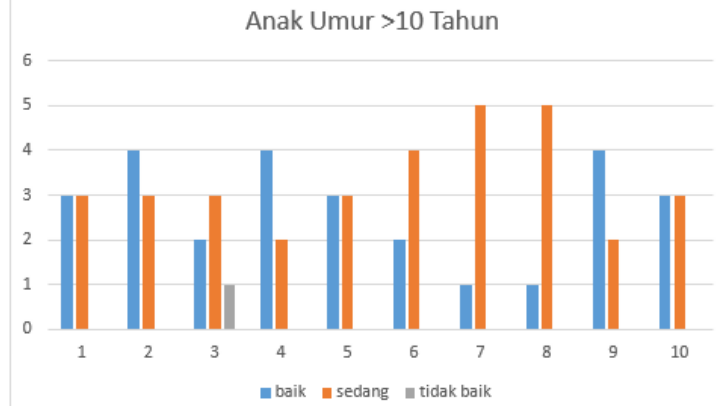

Gambar 6. Hasil Kuisioner Anak-anak

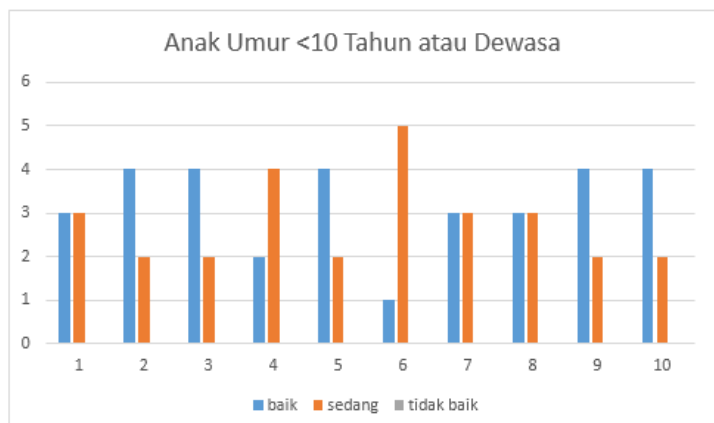

Gambar 7 Hasil Kuisoner Orang Dewasa

\section{Kesimpulan}

1) Berdasarkan penelitian yang sudah dilakukan, Game Save Forest Indonesia mampu memberikan pengetahuan mengenai informasi tentang jenis-jenis hutan di Indonesia dengan hasil tingkat kepuasan user dibawah umur 10 tahun $60 \%$ dan user di atas umur 10 tahun sebesar $80 \%$. Sedangkan implementasi metode Fuzzy dirasa telah dapat berjalan dengan baik dalam Game Save Forest Indonesia. Dengan demikian, menggunakan metode Fuzzy pada game ini dinilai menjanjikan untuk meningkatkan kecerdasan buatan serta kesulitan dalam game.

2) Pada pengembangan lebih lanjut dapat menambahkan membership function seperti jarak dekat, sedang dan jauh. Dan setiap enemy memiliki input fuzzy peluru dan darah sehingga enemy akan lebih fleksible jika berhadapan dengan player.

\section{Daftar Pustaka}

Agustinus Nilwan. 1998. "Pemrograman Animasi dan Game Profesional 4". Elex Media Komputindo.Jakarta

A. Naba. 2009. "Belajar Cepat Fuzzy Logic Menggunakan Matlab". Penerbit Andi. Yogyakarta.
Budi Raharjo. 2015. "Mudah Belajar C\#”. Informatika Bandung.

Dery Fathurochman, Wina Witanti, Rezki Yuniarti. 2014. "Perancangan Game Turn Based Strategy Menggunakan Logika Fuzzy dan Nä̈ve Bayes Classifier". Seminar Nasional Informatika 2014 (semnasIF 2014).

Dr. Widodo Budiharto, S.Si., M.Kom, Derwin Suhartono, S.Kom., MTI. 2014. "Artificial Intelligence". Penerbit Andi. Yogyakarta.

Supeno Mardi Susiki Nugroho, Yunifa Miftachul Arif, Mochamad Hariadi, Mauridhi H Purnomo. 2011. "Perilaku Taktis Untuk Non-Player Characters di Game Peperangan Meniru Strategi Manusia Menggunakan Fuzzy Logic dan Hierarchical Finite State Machine". Journal ISSN 0216-0544.

Wahana Komputer. 2014. "Mudah Membuat Game 3 Dimensi Menggunakan Unity $3 D$ ”. Penerbit Andi. Yogyakarta. 